EDITORIAL

\title{
Convergência na diversidade
}

Alvaro Chrispino ${ }^{\text {a }}$

Ao ler os artigos indicados para compor o número 107 da revista Ensaio, percebemos que são marcados pela diversidade de análise, pelo aceno à diminuição da desigualdade e, claro, pela convergência de propósitos de melhoria da Educação. Somos, imediatamente, levados ao passado, para as aulas de Jorge Ferreira, no Doutorado em Políticas Públicas e Gestão da Educação da Universidade Federal do Rio de Janeiro (UFRJ).

Desde o primeiro momento, os debates profícuos são orientados pela ideia de que, para melhor entendermos as origens dos problemas e decidirmos sobre trajetórias de solução em Educação, precisamos conhecer a formação do povo brasileiro e a gênese de problemas estruturais. Sem isso, corremos o risco de, por exemplo, gastarmos tempo, inteligência e recursos na ação sobre consequências, e não na causa.

Por tal, fazemos uma grande viagem cultural sobre as ideias de muitos e qualificados autores que tratam da formação do povo brasileiro a fim de conhecer como cada um deles trata a história de nossa formação e os "descaminhos" até os dias atuais. Com variações na estruturação da análise e na intensidade da narrativa, Manoel Bomfim (O Brasil na América: Caracterização da Formação Brasileira), Sérgio Buarque de Holanda (Raízes do Brasil), Caio Prado Junior (Formação do Brasil Contemporâneo), Gilberto Freyre (Casa Grande e Senzala), Darcy Ribeiro (O Povo Brasileiro) e Raimundo Faoro (Os Donos do Poder) apontam a trajetória da formação do povo brasileiro e apresentam um conjunto de explicações possíveis para melhor entendermos o que somos hoje, com nossas virtudes, contradições e lacunas sociais.

A mesma proposta é defendida por Antônio Candido, que assim sintetiza a questão do passado, que repercute até nossos dias, indicando os tópicos que merecem nosso estudo:

São fundamentais tópicos como os seguintes: os europeus que fundaram o Brasil; os povos que encontraram aqui; os escravos importados sobre os quais recaiu o peso maior do trabalho; o tipo

\footnotetext{
Centro Federal de Educação Tecnológica Celso Suckow da Fonseca, Rio de Janeiro, RJ, Brasil/Secretaria de Educação de Teresópolis, Teresópolis, RJ, Brasil.
} 
de sociedade que se organizou nos séculos de formação; a natureza da independência que nos separou da metrópole; o funcionamento do regime estabelecido pela independência; o isolamento de muitas populações, geralmente mestiças; o funcionamento da oligarquia republicana; a natureza da burguesia que domina o país. É claro que estes tópicos não esgotam a matéria, e basta enunciar um deles para ver surgirem ao seu lado muitos outros. Mas penso que, tomados no conjunto, servem para dar uma ideia básica.

Nesse contexto de complexidade e diversidade, a sociedade brasileira mantém a Educação enquanto aquela é dinamizada por esta e, ao mesmo tempo que a Educação transforma, é também transformada pela sociedade.

Tivemos a oportunidade de escrever que a gestão dos sistemas educacionais é um exercício complexo (CHRISPINO, 2016). Em síntese, temos que o sistema educacional brasileiro apresenta aspectos interessantes: é imenso e envolve a União, 26 estados, Distrito Federal e 5.570 municípios, com funções e obrigações definidas, mas interdependentes pois que oferecem um continuum em algumas áreas. Possui muitos perfis no que se refere a clientela: bebês, crianças, jovens, adultos, índios, negros, imigrantes, cidadãos de todas as idades e com necessidades especiais, alunos da zona rural, trabalhadores formais e informais, analfabetos estruturais e funcionais etc. Apresenta diversos níveis e modalidades: Educação Infantil, Ensino Fundamental, Ensino Médio, Graduação, Tecnólogos, Especializações, Mestrados e Doutorados (ambos com modalidades acadêmico e profissional), Educação de Jovens e Adultos, Educação Profissional (com centenas de diferentes cursos), Educação Especial, Educação Indígena... sem esquecer que esses tipos e modalidades podem sofrer combinações variadas nas escolas. Mantém órgãos normativos de sistemas educacionais nos três entes federativos. Possui um corpo qualificado e ativo de profissionais, mas com formações distintas e realizadas em tempos diferentes. Reúne uma comunidade à sua volta e, em geral, uma família vinculada a cada aluno com suas expectativas de futuro e entendimento sobre o passado que quer ver reproduzido nas gerações contemporâneas. A escola é, pois, o espaço para onde convergem diferentes visões de mundo, tornando-se um grande espaço de tensões e aproximações de ideias e valores, ora conservadores, ora progressistas. "A gestão de sistemas educacionais é o que se chama em Direito um hard case (caso difícil), considerando sua complexidade" (CHRISPINO, 2016, p. 101).

Se percebemos a complexidade na construção da sociedade, nos sistemas educacionais, por que essa mesma complexidade pouparia a estrutura escolar? Pelo que nos apresenta Gomes (2005), em seu denso texto: 
A estrutura peculiar dos sistemas educacionais assemelha-se a uma cebola, com sucessivas camadas que influenciam a aprendizagem. Assim, destacam-se despesas, instalações, tempo letivo, professores, clima e gestão escolares, efeitos dos colegas, alocação da matrícula e do espaço, ações que contribuem para a efetividade na sala de aula e para a formação de turmas. Portanto, é possível atuar sobre os fatores intra-escolares, no seu âmbito de influência, que têm papel mais amplo nos países em desenvolvimento.

Mais uma vez, enumeram-se as diversidades na esperança de que seus estudos, análises e intencionalidades possam convergir no sentido essencial da Educação: a aprendizagem dos estudantes.

Buscamos entender, nas trajetórias de formação, por que a Educação, representada pelos atores de seus sistemas, é lente na execução de mudanças estruturais (CHRISPINO; BAYMA; REZENDE, 2012). Podemos dizer, s.m.j., que não há problema novo ou fato relevante na Educação nos últimos 29 anos. Há remendo novo em problema antigo, ou rótulo novo em conteúdo antigo. A última grande surpresa da Educação brasileira deu-se a partir de importante constatação de Ribeiro (1991) sobre o equívoco, até então mantido pelos gestores educacionais e sociedade, de culpar a evasão pelos problemas da Educação brasileira. Combatíamos a evasão, quando, na verdade, deveríamos dar atenção à repetência. Passados quase 30 anos desde essa constatação, podemos elencar algumas observações de Ribeiro (1991, p. 18), à época, para refletirmos na e para a mudança:

Aos pais interessa mais a frequência à escola do que a sua qualidade. E impressionante o fato de que no Brasil, hoje, a população escolar frequente a escola de $1^{\circ}$ Grau, em média, por mais de 8,5 anos, conseguindo terminar, em média, apenas 6 séries. E nada ou pouco se sabe, do ponto de vista cognitivo, o que significam estas 6 séries. [...] Parece que a prática da repetência está contida na pedagogia do sistema como um todo. É como se fizesse parte integral da pedagogia, aceita por todos os agentes do processo de forma natural. A persistência desta prática e da proporção desta taxa nos induz a pensar numa verdadeira metodologia pedagógica que subsiste no sistema, apesar de todos os esforços no sentido de universalizar a educação básica no Brasil (RIBEIRO, 1991, p.18, grifos nossos).

Ainda sobre a dificuldade de mudança, podemos enumerar a complexidade da transformação social em contraponto à dinâmica lenta do universo educacional 
apresentada por Serres (2011) - filósofo, membro da Academia Francesa, em discurso em sessão solene no Institut de France sobre os "Os Novos Desafios da Educação", a propósito dos resultados dos estudantes franceses de 15 anos de idade, na pesquisa do Programa Internacional de Avaliação de Alunos/Organização para a Cooperação e Desenvolvimento Econômico (Pisa/OCDE) - em sua obra Polegarzinha, cujo nome se deve ao fato de as crianças digitarem em aparelhos de smartphone inclusive com o polegar.

Raríssimas na História, essas transformações, que chamo "hominescentes", criam, no meio do nosso tempo e dos nossos grupos, uma fratura tão larga que poucos olhares mediram seu verdadeiro tamanho.

Comparo-a, repito, às fraturas que ocorreram no neolítico, na alvorada da ciência grega, no início da Era Cristã, no fim da Idade Média e no Renascimento.

Na margem jusante dessa falha estão jovens, aos quais pretendemos dispensar ensino, em âmbitos que datam de uma idade que eles não mais reconhecem: prédios, pátios de recreio, salas de aula, mesas, cadeiras, auditórios, campi, bibliotecas, laboratórios até, eu ia dizer até saberes... âmbitos que datam, digo, de uma idade e adaptados a uma era em que os homens e o mundo eram o que não são mais (SERRES, 2011, não paginado, grifos nossos).

O número da Ensaio é inaugurado por uma importante questão levantada por Monica Ribeiro da Silva (UFPR), após constatar que a matrícula no Ensino Médio decai progressivamente a partir de 2004, quando a legislação indica sua obrigatoriedade. Houve uma queda de 9 milhões de pessoas matriculadas em 2004, chegando a um número inferior a 8 milhões, em 2017. Pergunta ela: O que essa diminuição significa em um contexto em que a legislação sinaliza para a ampliação do direito à Educação para a faixa etária considerada apropriada para estar no Ensino Médio? O esforço pelo Direito à Educação começa em 1971 quando passamos da obrigatoriedade de quatro para oito anos, em primeiro confronto para diminuição da exclusão, e continuamos o embate em 2009 com a obrigatoriedade até os 17 anos. Lá se vão 38 anos... As conclusões da pesquisadora são elucidativas tanto quanto provocativas.

$\mathrm{O}$ artigo seguinte se intitula What do children know upon entry to pre-school in Rio de Janeiro? (O que as crianças sabem ao ingressar na pré-escola na cidade do Rio de Janeiro?) e é apresentado por Bartholo, Koslinsk e Costa, da UFRJ, e Barcellos, 
do IDados. Após aplicação de regressão multivariada, os autores informam que "conhecer as diferenças no momento inicial da escolaridade associadas às características do contexto familiar pode ajudar a entender o desenvolvimento infantil no início da pré-escola e, assim, identificar políticas e práticas potenciais que possam reduzir essas desigualdades durante a pré-escola" e concluem que (i) idade é um importante preditor para o desenvolvimento cognitivo das crianças no ingresso do período obrigatório de escolarização; b) educação dos pais é o principal preditor considerando as características da família; c) o indicador de ambiente educativo do lar sugere uma associação positiva com o teste cognitivo, mesmo após controle das variáveis socioeconômicas e idade. Esse é um tema necessário quando debatemos diminuição de desigualdade e inclusão.

O terceiro artigo retoma um tema bastante conhecido dos leitores da Ensaio: a violência escolar ou, como preferimos, a convivência escolar. Adriana Carro Oliveira e José Alfonso Lima Gutiérrez apresentam pesquisa realizada em duas escolas mexicanas e chamam atenção para o grande dilema das políticas públicas educacionais que é como alcançar a todos os atores sem que eles percam a sua singularidade ou, em outras palavras, como diferenciar a execução de políticas gerais e manutenção das características locais das escolas e/ou comunidades. Ao final, apontam para a importância da participação de diretores e professores para o sucesso das políticas públicas propostas.

O artigo seguinte é assinado por Izmailova, Sheinova e Soldatenko, todas da Moscow State University of Humanities and Technology. Ao abordarem a competência em línguas estrangeiras, a aprendizagem precoce e a interação entre pais e familiares, os autores apontam a "influência da participação dos pais na competência, motivação, atitude e abertura para aprender línguas estrangeiras, bem como a ansiedade psicológica dos pré-escolares em relação à percepção da fala estrangeira". A temática é bem-vinda especialmente por causa da onda recente de escolas bilíngues que vemos surgir no Brasil.

O quinto artigo aproxima-se das temáticas gerais da diversidade e (diminuição da) desigualdade, apresentando análises e resultados que satisfazem ao quesito da convergência para com o propósito da Educação de qualidade para todos. Os autores Souza (Universidade Federal de Pernambuco - UFPE) e Costa (Universidade Federal Rural de Pernambuco - UFRPE) tratam de um tema primordial para a garantia das condições de permanência de estudantes no Ensino Superior: o Programa Nacional de Assistência Estudantil (Pnaes), conforme aplicado na UFRPE. As conclusões apontam para as conquistas, mas também 
para as fragilidades encontradas, que podem e devem ser superadas a fim de que os programas desse tipo alcancem sua real finalidade.

A seguir, temos outro conjunto de temas muito comum na história da Ensaio, que é a avaliação, tanto a avaliação externa, quanto a da aprendizagem. E, lembramos que esses temas são essencialmente controversos e acolhem a diversidade de resultados, variando do fundamento teórico que se utilizam como ponto de apoio. Fernandes e Gomes (Universidade Federal de Minas Gerais - UFMG) dirigiram sua pesquisa para o Programa de Avaliação da Aprendizagem Escolar (Paae), aplicado à Rede Pública Estadual de Ensino de Minas Gerais e realizaram suas ações junto a professores da disciplina de História. Concluem que "os resultados revelam uma assimetria entre o discurso e a prática. Embora a maioria dos professores utilize o Paae, no papel de política pública de avaliação, ele não tem alcançado os resultados esperados pelos gestores e idealizadores". A conclusão parece apontar para a conhecida dificuldade de implementação de políticas públicas em sistemas educacionais, possivelmente por conta da diversidade, singularidade e autonomia das unidades que o compõem.

O sétimo artigo é, também, sobre um tema controverso e que, como tal, possui defensores e adversários com argumentos dos mais diversos. Rankings acadêmicos ou universitários no Chile é o tema dos autores Francisco Ganga-Contreras, Walter Sáez, Adolfo-Ignacio Calderón e Ángel Calderón. Abordam a comparação ente rankings internacionais e chilenos, com propostas de categorização e análise de critérios utilizados. Certamente, os fundamentos, metodologia, resultados e discussão poderão ser absorvidos pela comunidade brasileira, uma vez que esse tema "nunca esfria".

O oitavo artigo trata de um tema que simboliza uma desigualdade histórica no Brasil: a alfabetização. Parece não haver dúvidas quanto ao fato de vivermos uma crise de aprendizagem. Os resultados das diversas avaliações de larga escala, quer nacionais, quer internacional, deixam claro essa crise. Ela, certamente, precisa considerar a alfabetização, ou a falta dela, senão como gênese, certamente como fator preponderante. Temos uma alfabetização historicamente tardia e de baixa qualidade atualmente. Schneider, Grosch e Dresch estudam o Pacto Nacional pela Alfabetização na Idade Certa (Pnaic) e sua contribuição na formação dos professores alfabetizadores de Lages, em Santa Catarina. Apesar do momento importante para o tema em todo o Brasil, os autores concluem que "a formação continuada, apesar de proporcionar momentos de estudo teórico e prático, não chegou a provocar mudanças conceituais significativas", convidando-nos, novamente, a entender como as 
políticas públicas educacionais podem, de fato, contribuir para sua efetividade no mundo real da escola. Eis um desfio que se renova!

O artigo de número nove retoma os estudos em torno da desigualdade no Ensino Superior. Só que agora, os autores focam os estudos sobre a situação de egressos e evadidos de quatro cursos superiores do Distrito Federal, resultantes da política de expansão do Ensino Superior. A efetividade dessa política pública é posta em dúvida por Almeida, Neres, Nunes e Souza Júnior, todos da Universidade de Brasília (UnB), visto que seus estudos demonstram "um alto número de alunos desempregados e, entre os empregados, poucos trabalham na sua área de formação, levantando dúvidas da efetividade da política de expansão de vagas no Ensino Superior realizada no Brasil”.

O artigo de número 10 desse conjunto, trabalha o tema tolerância como norteador de suas discussões, e solicita nossa reflexão sobre a contribuição (ou não) das divisões em grupamentos culturais no processo de aprendizado da tolerância. A pergunta apresentada é se a identificação cultural - tão necessária para mapear os modos de vida, práticas e liberdades e caracterizar grupos culturais -, considerando as definições de territórios próprios, produzem os mesmos limites para os relacionamentos necessários. A pesquisa de Graff e Lopes, tal qual o fio de Ariadne no labirinto, nos conduzem em interessante argumentação para melhor refletirmos, mais uma vez, sobre diversidade de ideias e convergência de propósitos na Educação.

Escreveu Gomes (1999, p. 267) que "a qualidade do ensino certamente não se reduz ao desempenho dos alunos nos testes de rendimento, mas incontestavelmente o inclui”. Logo, pesquisas e discussões que possam aprimorar os debates sobre o uso da avaliação e a análise de seus resultados como ferramenta de efetivação e direitos é sempre bem-vinda. Nessa direção, Rodrigo Travitzki apresenta um estudo sobre o grau de incerteza do Índice de Desenvolvimento da Educação Básica (Ideb), a fim de aprimorar sua utilização, visto que seu uso, como já escreveram, "significou uma grande e positiva mudança no debate educacional brasileiro", solicitando mais e melhores informações para que alcance suas finalidades. O título "Qual é o grau de incerteza do Ideb e por que isso importa" é, por si só, um grande convite à leitura e à reflexão.

O artigo de Página Aberta traz provocações: a Educação para o século XXI e a aprendizagem ao longo da vida, dentre outras. Após ampla pesquisa em bases literárias, visitas e entrevistas, os autores Chiappe, Ternent de Sampe, Wills e Restrepo, todos da Universidad de La Sabana, Colômbia, apresentam muitas 
conclusões, de onde extraímos algumas para reflexões: "Se alguma escola considerar os resultados aqui como um guia estratégico, descobrirá rapidamente que eles não são universalmente aplicáveis; sua pertinência é claramente uma função do contexto social em que são revisadas". "Novas Pedagogias" não são realmente consideradas novas, elas estão aparecendo com um novo potencial como "belezas adormecidas" e, por fim, "Um ecossistema de aprendizado digital - e o aprendizado ao longo da vida - deve ser mais do que um mero substrato de apoio à aprendizagem; deve ser um espaço no qual todas as categorias mencionadas nos resultados sejam organizadas e possam se desenvolver e articular complexas interações entre atores educacionais com base na sinergia sociotécnica". Certamente um bom convite à leitura.

Esse conjunto de artigos que entregamos aos leitores da Ensaio são, pois, o melhor exemplo de leitura plural e densa, da diversidade de visão, de análise e de temas, sempre preocupados com as desigualdades que precisam ser superadas e orientados pela convergência de propósitos em contribuir para que a Educação cumpra seus maiores e melhores objetivos junto àqueles que ela alcança por meio dos diversos níveis e sistemas de ensino.

Boa leitura! 


\section{Referências}

CANDIDO, A. Antonio Candido inidica 10 livros para conhecer o Brasil. Blog da Boitempo, São Paulo, 17 ago. 2013. Disponível em: https:// blogdaboitempo.com.br/2013/05/17/antonio-candido-indica-10-livros-paraconhecer-o-brasil/. Acesso em: 16 fev. 2020.

CHRISPINO, A. Introdução ao estudo das Políticas Públicas: uma visão interdisciplinar e contextualizada. Rio de Janeiro: Editora FGV, 2016.

CHRISPINO, A.; BAYMA, F.; REZENDE, F. P. Análise e proposta de formação de educadores e administradores em Políticas Públicas. Ensaio: Avaliação e Políticas Públicas em Educação, Rio de Janeiro, v. 20, n. 76, p. 555-586, jul./set. 2012. https://doi.org/10.1590/S0104-40362012000300008

GOMES, C. A. A escola de qualidade para todos: abrindo as camadas da cebola. Ensaio: Avaliação e Políticas Públicas em Educação, Rio de Janeiro, v. 13, n. 48, p. 281-306, jul./set. 2005. https://doi.org/10.1590/S010440362005000300002

GOMES, C. A. Sucesso e fracasso no ensino médio. Ensaio: Avaliação e Políticas Públicas em Educação, Rio de Janeiro, v. 7, n. 24, p. 259-280, jul./ set. 1999.

RIBEIRO, S. C. A pedagogia da repetência. Estudos Avançados, São Paulo, v. 12, n. 5, p. 7-21, maio/ago.1991. https://doi.org/10.1590/S010340141991000200002

SERRES, M. Polegarzinha. Rio de Janeiro: Bertrand Brasil, 2011.

\section{Informações do autor}

Alvaro Chrispino: Professor dos Programas de Pós-Graduação de Ciência, Tecnologia e Educação e de Engenharia de Produção e Sistemas do Centro Federal de Educação Tecnológica Celso Suckow da Fonseca do Rio de Janeiro. Secretário de Educação de Teresópolis. Bolsista de Produtividade em Educação pelo Conselho Nacional de Desenvolvimento Científico e Tecnológico. Contato: alvaro.chrispino@gmail.com

(iD) https://orcid.org/0000-0001-9914-3471 